\title{
ManyBirds: A Multi-Site Collaborative Open Science Approach to Avian Cognition and Behavior Research
}

\author{
Megan L. Lambert ${ }^{1}$, Benjamin G. Farrar², Elias Garcia-Pelegrin ${ }^{2}$, Stephan Reber $^{3}$, \\ and Rachael Miller ${ }^{2,4 *}$ \\ ${ }^{1}$ Messerli Research Institute, University of Veterinary Medicine Vienna, Austria \\ ${ }^{2}$ Department of Psychology, University of Cambridge, UK \\ ${ }^{3}$ Department of Cognitive Science, Lund University, Sweden \\ ${ }^{4}$ School of Life Sciences, Anglia Ruskin University, UK \\ *Corresponding authors (Emails: rmam3@cam.ac.uk; megan.lambert@vetmeduni.ac.at; manybirdsproject1@gmail.com)
}

Citation - Lambert, M. L., Farrar, B. G., Garcia-Pelegrin, E., Reber, S., \& Miller, R. (2022). ManyBirds: A multisite collaborative Open Science approach to avian cognition and behavior research. Animal Behavior and Cognition, 9(1), 133-152. https://doi.org/10.26451/abc.09.01.11.2022

\begin{abstract}
Comparative cognitive and behavior research aims to investigate cognitive evolution by comparing performance in different species to understand how these abilities have evolved. Ideally, this requires large and diverse samples; however, these can be difficult to obtain by single labs or institutions, leading to potential reproducibility and generalization issues with small, less representative samples. To help mitigate these issues, we are establishing a multi-site collaborative Open Science approach called ManyBirds, with the aim of providing new insight into the evolution of avian cognition and behavior through large-scale comparative studies, following the lead of exemplary ManyPrimates, ManyBabies and ManyDogs projects. Here, we outline a) the replicability crisis and why we should study birds, including the origin of modern birds, avian brains and convergent evolution of cognition; b) the current state of the avian cognition field, including a 'snapshot' review; c) the ManyBirds project, with plans, infrastructure, limitations, implications and future directions. In sharing this process, we hope that this may be useful for other researchers in devising similar projects in other taxa, like non-avian reptiles or mammals, and to encourage further collaborations with ManyBirds and related ManyX projects. Ultimately, we hope to promote collaboration between ManyX projects to allow for wider investigation of the evolution of cognition across all animals, including potentially humans.
\end{abstract}

Keywords - Animal cognition, Birds, Comparative psychology, Replication, Metascience, Open science

Cognition may be broadly defined as including perception, learning, decision-making and memory (Shettleworth, 2010). A key aim of comparative cognitive research centers around understanding the variation in cognitive traits across species, in order to gain insight into the selective pressures that drive their evolution (Shettleworth, 2010; Thorndike, 1911). To do so ideally requires data from a large number of individuals and species using methods that generate reliable cross-species comparisons; however, these remain two of the major challenges faced by the field (Krasheninnikova et al., 2020).

These issues have been raised early on in the field's history, starting most notably with Beach's (1950) criticism of comparative psychology for the limited number of topics studied in very few species, which precluded the field's original aim to derive and test theories through multi-species comparisons (Thorndike, 1911). The basis for these comparisons was additionally cited as lacking a strong theoretical foundation and failing to consider species' shared history (Hodos \& Campbell, 1969). Yet despite the established importance of large and diverse samples, collecting this level of data remains a significant 
hurdle in comparative cognition research today, as large samples of individuals or species can be difficult to obtain by single labs or institutions, due to aspects that include funding and space for animal facilities, as well as labor and time availability of researchers (Stevens, 2017). More commonly, research groups tend to focus their efforts on one or two model species, often with relatively low sample sizes, to address a range of questions or topics. The results from these studies are then often assumed to reflect the abilities of the species in question. However, such small samples raise questions about the generalizability and replicability of the results (Farrar et al., 2021; but see Smith \& Little, 2018). Additionally, they limit our understanding of how cognition may vary within a species or population, factors which are critical to understanding its evolution (Chittka et al., 2012; Völter et al., 2018).

Although the diversity of species involved in comparative cognitive research has increased substantially in the 50+ years since Beach's (1950) original commentary, the field still faces similar challenges today. As highlighted by Krasheninnikova et al. (2020), there is still a paucity of direct, largescale phylogenetic comparisons that would allow for robust inferences to be made regarding the distribution and evolution of particular cognitive abilities. Indeed, most direct comparisons involve just a handful of species (often two) - far below the estimated 20 species required to make reliable phylogenetic comparisons (Freckleton et al., 2002). More commonly, results from single research groups are considered alongside comparable data from other labs and species; however, even minor methodological differences between studies can significantly impact results and preclude meaningful comparisons (Barth et al., 2005). As subjects are often tested repeatedly with a range of tasks, members of the same species housed at different research sites can exhibit striking differences in performance on identical tasks as a result of their testing history or a range of other factors (Stevens, 2017). Consequently, introducing heterogeneity by sampling from more individuals across a range of conditions (such as from different research sites) is a necessary step forward (Farrar et al., 2021).

In recent years, there has been a growing push to form large-scale, multi-lab collaborations aimed at collecting truly comparable data across a large number of species, specifically to target these weaknesses (e.g., Krasheninnikova et al., 2020; MacLean et al., 2014; Stevens, 2017). For example, Maclean et al. (2014) organized a large-scale comparative study of motor-self regulation across 567 individuals representing 36 species of mammals and birds with the aim of understanding the evolution of self-control. More recently, there has been the formation of several 'ManyX' projects with dedicated infrastructure for ongoing, collaborative data collection across labs, beginning with the ManyBabies Project (e.g., ByersHeinlein et al., 2020) and the Open Science Collaboration (2015) in response to the replication crisis within psychology. Following on from this, the ManyPrimates project was launched, which has enabled researchers to collect and compile data from over 176 individuals representing 12 primate species (ManyPrimates, Altschul, Beran, Bohn, Call, et al., 2019; ManyPrimates, Altschul, Beran, Bohn, Caspar, et al., 2019). These efforts provide an encouraging way forward and a viable means of addressing issues of sample size, replicability, and generalization, and can be extended to other taxa (such as the planned ManyDogs project).

The avian clade consists of over 10,000 living species that cover the globe and represent a vastly diverse range of ecological niches, social structures, life histories, and foraging habits (Gill et al., 2021). Moreover, the field of avian cognition has been steadily expanding, particularly over the last two decades, to incorporate research on more species in both field and lab settings. Most notably, comparisons between corvids (and more recently parrots) and primates have revealed striking similarities in cognitive abilities that have generated extensive discussion into the convergent evolution of cognition in these taxa, which last shared a common ancestor some 324 million years ago (Dos Reis et al., 2015; Emery \& Clayton, 2004; Lambert et al., 2019; Miller et al., 2019; Van Horik et al., 2012). Despite the growth of avian cognition research, the field still only encompasses a small proportion of all extant bird species - we therefore lack vital data and species representation to enable reliable inter- and intra-species comparisons within birds and other taxa which would provide reliability in interpretation. For example, inclusion of more crow species to a wider data set on self-control significantly improved overall performance of birds compared with apes (Kabadayi et al., 2016; MacLean et al., 2014). As a growing area of research, avian cognition is well placed to undertake similar large-scale collaborative efforts. 
We are in the process of developing a "ManyBirds" project (Figure 1), with the aim of establishing an efficient and sustainable Open Science based framework for conducting multi-site studies of avian cognition. The primary project aim is to provide new insights into the evolution of avian cognition through comparative studies, following the lead of exemplary ManyBabies (e.g., Byers-Heinlein et al., 2020), ManyPrimates (ManyPrimates, Altschul, Beran, Bohn, Call, et al., 2019; ManyPrimates, Altschul, Beran, Bohn, Caspar, et al., 2019) and ManyDogs projects, such as testing the impact of socio-ecological factors, underlying evolutionary mechanisms and construct validity of cognitive abilities (ManyPrimates, Altschul, Beran, Bohn, Caspar, et al., 2019). We aim to include as many avian species and subjects as possible from a variety of lab, zoo, farm, private residence and field sites, by pooling resources world-wide and facilitating collaboration, open discussions, expertise sharing, and the development of new study designs and ideas. It should enable improved replicability (e.g., test/re-test) and generalizability, with remote accessibility for all.

Figure 1

The ManyBirds Project Logo

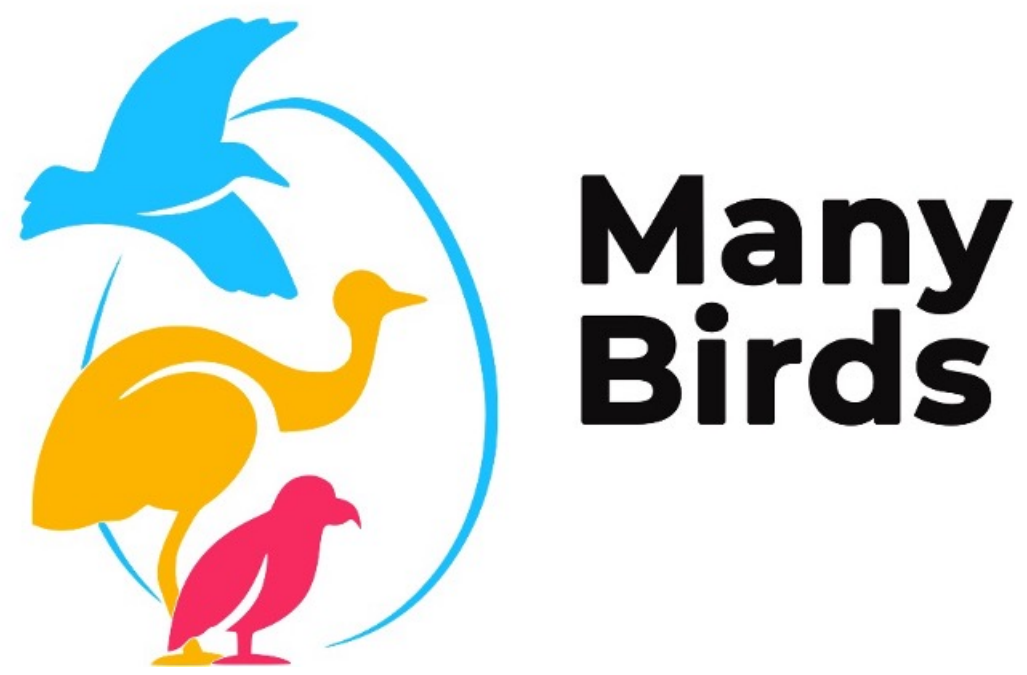

Note. Credit to Stephan Reber and Emma Arbeau, 2021.

In this article, we focus on: a) why birds, including avian brains and convergent evolution; b) the current state of the avian cognition field, including a 'snapshot' review of avian cognition from 2015-2020, across 30 journals and 550+ articles; c) the ManyBirds project, including project plans, current stage, limitations, implications and future research.

\section{ManyX Projects and the Replication Crisis}

ManyX projects have in part been motivated by psychology's replication crisis, and there is growing recognition that such replicability issues might affect animal cognition too (Beran, 2018; Brecht et al., 2021; Farrar et al., 2021; Schubiger, 2019; Stevens, 2017; Tecwyn, 2021). Through a combination of false-positive inflating research practices and a publication bias against negative results (Bishop, 2019), literatures can soon be populated by statistical effects that are large overestimates (Gelman \& Carlin, 2014), and that often fail to replicate in new samples (Open Science Collaboration, 2015). In the human literature, multi-site studies were necessary to provide strong tests of scientific hypotheses with high statistical power and heterogeneous samples of participants, settings, and experimenters (Klein et al., 2014, 2018; Würbel, 2000). Such benefits may be heightened in fields with many unique samples, such as animal cognition 
(Lange, 2019). In these fields, multi-site collaborations offer the opportunity to test the replicability and generalizability of effects, both within- and between-species, in addition to stronger tests of evolutionary hypotheses (ManyPrimates et al., in press; ManyPrimates, Altschul, Beran, Bohn, Call, et al., 2019; ManyPrimates, Altschul, Beran, Bohn, Caspar, et al., 2019). However, perhaps one of the key early benefits of ManyX projects in animal cognition will be in understanding just how much variation occurs across different samples of the same species between test sites, as this will provide indirect evidence for the likely robustness of many previously published effects, and consequently the robustness of the between-species comparisons that are central to comparative cognition. These ManyX approaches are therefore necessary across a range of taxa, including mammals, birds and reptiles.

\section{Why Birds?}

\section{The Origins of Modern Birds}

In contrast to all other ManyX projects to date, the subjects of ManyBirds are not mammals but birds, which are reptiles and the last remaining dinosaurs. The direct ancestors of modern birds most probably split from non-avian dinosaurs in the middle Jurassic period (Xu et al., 2011). They evolved and diversified for approximately 100 million years before the Cretaceous-Paleogene extinction, which marked the end for all other dinosaurs (Jarvis et al., 2005). The diversity of birds that existed at that time almost completely disappeared as well. Only a few taxa of one of at least five major bird clades survived, the Neornithes (Longrich et al., 2011). It has been suggested that the surviving species were relatively small birds, capable of flight, which primarily lived on the ground and in the undergrowth (Field et al., 2018). After the extinction, these few species gave rise to the diversity of birds seen today. However, the major clades appear to have already originated in the late Cretaceous (Prum et al., 2015). The Neornithes had already split into Palaeognathae (today represented by ostriches, emus, kiwis, tinamous etc.) and Neognathae, which in turn had split into Galloanserae (the ancestors of fowl, such as chickens and ducks) and Neoaves (all other birds, including passerines).

Today, birds are found on all continents, and they occupy almost every niche available to tetrapods. During diversification, they encountered very similar socio-ecological challenges as mammals, and these selected for highly comparable cognitive capacities (Emery \& Clayton, 2004; Lambert et al., 2019). Due to the very different evolutionary history of birds, their cognition did not evolve from the same substrate (see section "The convergent evolution of cognition"). Hence, a large-scale comparison of the cognition of different bird species will allow us to understand the evolution of avian cognition as well as explore how the same selective pressures shape cognition in very different lineages.

\section{Avian Brain}

A further justification for focusing on birds is that the structure of the avian brain has significant similarities as well as differences to the mammalian brain. The avian brain is organized in nuclei and does not have a laminated cortex. For a long time, it was thus thought that the cerebrum of birds was primitive and consisted almost entirely of striatal regions. We know today that, like in mammals, the vast majority of it is actually pallium (Jarvis et al., 2005). The different nuclei are also interconnected similarly to the different layers of the mammalian neocortex (Jarvis et al., 2005). The basic "neuroarchitecture" of birds and mammals appears to share many more similarities than previously thought. They both have orthogonally organized networks of fibres, which radially connect areas of sensory input with regions for motor functions and tangentially associate areas of similar processing levels (Stacho et al., 2020). The neurons themselves are highly conserved as well: several transcription factors are identical (demonstrated by gene expression experiments) across mammals and birds (Briscoe et al., 2018). In short, the pallium (forebrain) of amniotes (vertebrates that undergo embryonic or foetal development within an amnion, including mammals, birds, other reptiles) can be organized in a variety of ways, but the different structures can still enable comparatively complex cognitive capacities (Güntürkün, 2005). For the purposes of the 
ManyBirds project, it is mainly important to note that the avian brain is not a primitive version of the mammalian one (Jarvis et al., 2005).

The pallium in mammals contains the prefrontal cortex, a part of the frontal lobe, which is the main seat of executive functions, such as working memory, motor self-regulation, and decision-making (Diamond \& Bond, 2003). The prefrontal cortex is disproportionally large in primates, particularly humans (Brodmann, 1909; Donahue et al., 2018) and hence generally considered vital for sophisticated cognitive capacities. In birds, which lack a cortex, the equivalent brain region is the nidopallium caudolaterale (NCL). It lies at the other end of the pallium to the prefrontal cortex. The two regions are on the structural level, to the best of our knowledge to date, not shared by common ancestry (Shubin et al., 2009). However, they strongly resemble each other in connectivity and chemoarchitecture (Güntürkün, 2005, 2012). This is perhaps most apparent when looking at dopamine, the neurotransmitter involved in selecting, maintaining, and processing information and in generating corresponding responses. The prefrontal cortex and the nidopallium caudolaterale are both innervated by dopamine via the ventral tegmental area and the substantia nigra, and their neurons are activated by D1 receptor cascades (Durstewitz et al., 1998). Both also receive input from all sensory modalities and their output gets sent to the motor structures (Jacobs et al., 2019).

The nidopallium caudolaterale is well documented to be the seat of executive functions in birds (for reviews see Güntürkün, 2005, 2012; Güntürkün \& Bugnyar, 2016). For instance, pigeons (Columba livia) show deficits in delayed alternation and working memory tasks when the area of the NCL is lesioned, and the reduction in performance is proportional to the size of these lesions (Diekamp et al., 2002; Güntürkün, 1997). Additionally, single-neuron responses were measured in the NCL of carrion crows (Corvus corone) during a visual detection task (Nieder et al., 2020). The crows' neuronal responses, shortly before providing feedback, correlated with the choices they made (correct or incorrect) rather than the actual stimulus intensity. This study provided strong evidence for sensory consciousness in birds.

Given the importance of the NCL for sophisticated cognition, it should be expected that birds with larger NCLs should perform at higher levels in cognitive tasks. Such allometries have been known for the prefrontal cortex in mammals for over a century (Brodmann, 1909) - recent research showed that the same might apply for the NCL in birds. Von Eugen et al. (2020) mapped the NCL in chickens (Gallus gallus domesticus), pigeons, zebra finches (Taeniopygia guttata) and carrion crows. They found that the NCL is more derived (denser, higher parcellation) in Passeriformes than in pigeons, and that NCL is larger in pigeons than chickens The most elaborate version was observed in the carrion crow, a corvid known for particularly sophisticated cognitive capacities. Executive function performance might indeed correlate with the extent of the NCL, at least in Neoaves. In the classic cylinder task, which tests for motor self-regulation, zebra finches performed better than pigeons, and ravens (Corvus corax; close relatives of the carrion crow) outperformed the finches (Kabadayi et al., 2016; MacLean et al., 2014). These results would be expected given the relative size of the NCL in these species (Von Eugen et al., 2020).

Bird brains are significantly smaller than mammalian brains, but they are still capable of highly comparable cognitive performance (Seed et al., 2009). One suggested explanation is that there are disproportionately more neurons in the avian pallium. The number of neurons in this part of the brain might indeed reflect levels of cognitive performance better than absolute or relative brain size (Herculano-Houzel, 2017; Jacobs et al., 2019). The pallium of some birds, such as corvids and large-brained parrots, contains an equal amount, or more, neurons than the forebrain of much larger primates (Olkowicz et al., 2016). For instance, the pallium of a raven has slightly more neurons than that of a capuchin monkey although it is only a quarter of the weight (Olkowicz et al., 2016). A ManyX approach focusing on birds enables further exploration of the influence of brain structure on cognitive evolution.

\section{The Convergent Evolution of Cognition}

Their evolutionary history, extreme diversity, and brain structure make birds ideal candidates for large scale multi-species comparisons, which in concert with the other ManyX projects can decisively advance our understanding of cognitive evolution. The cognitive capacities of several corvids and parrots has been suggested to rival those of primates in complexity (Emery \& Clayton, 2004; Lambert et al., 2019). 
Similar social-ecological selection pressures may have led to this convergent evolution. However, in order to truly understand how avian cognition evolves, we need to test many more bird orders. Historically, avian research has focused on pigeons and quail, and more recently corvids, parrots, and several other Passeriformes; however, other lineages are distinctly underrepresented. For example, our review found no studies on Palaeognathae, one of the two major bird clades, which has five distinct orders. Furthermore, other bird lineages have adapted to unusual niches, such as penguins and flamingos, and we do not know how this affected their cognition. Many bird species are still to be investigated using a comparative approach to provide the opportunity to trace the evolution of cognition. We purposely did not limit this planned project to a specific bird lineage.

By including as many species and individuals as possible, in labs, zoos, private residences and the field, the ManyBirds project will be able to test several hypotheses about cognitive evolution and compare behavior and cognitive performance both within (including between sites) and between species. A large sample of different species is crucial for the success of this endeavor. There are many hypotheses aiming to explain the evolution of mammalian, and ultimately human, cognition. Our project could validate or challenge these hypotheses by studying the evolution of cognition in birds, which are evolutionarily distant to mammals. In other words, hypotheses on cognitive evolution, which are confirmed in two very different lineages, can be considered to have more support.

\section{State of the Field}

\section{Methods}

In order to gain a broad overview of contemporary avian cognition research including the species, topics, and sites of study, we reviewed the recent avian cognition literature from 2015-2020, across select journals, encompassing 550+ articles (from an initial output of 2,050 articles). We focused on 30 journals relevant to avian/animal cognition (15 of which overlap with journals reviewed by ManyPrimates, Altschul, Beran, Bohn, Caspar, et al., (2019)) and exported relevant articles from the Web of Science database using a keyword search (terms: ((avian OR bird) AND (cogniti* OR intell* OR psycholog*)) + (((physical OR social OR technical) AND (cogniti* OR intell*)) OR memory OR learn* OR atten*). For five select journals that were likely to yield the highest number of papers related to avian cognition, we exported all published papers within the specified time frame and reviewed titles and abstracts by hand. For both keyword and hand searches, our criteria for inclusion in the review were i) the paper included data from at least one bird species, ii) the paper included an experimental manipulation, and iii) the topic was cognition or relevant psychological phenomenon as defined by Shettleworth (2010). Our date criteria of 2015-2020 included articles published online in 2020, but with a print publication date of 2021.

We ran two pilot coding trials, where each of the five coders followed a coding guideline to code a small subset of data. Following each pilot, we reconvened to discuss and confirm the final coding guidelines, before dividing the data set between coders and proceeding to code the data. We began by sifting by title and abstract according to the selection criteria. We then coded each relevant article using the same format of excel sheet (see data availability statement for link to data). We acknowledge that our search methods, like many other primarily keyword search-based reviews, may not result in a fully comprehensive sample of all possible available avian cognition studies from 2015-2020. However, in using a predetermined keyword search, plus hand-searching a selection of the most relevant journals, we aimed to produce a reliable overview which is sufficient for the main purposes of this review (i.e., focusing on general topic, sample size, sites and species representation). For included studies, we coded multiple types of information (see Table 1).

\section{Results}

In total, we extracted data from 562 avian cognition studies from 2015-2020. Five additional articles from 2021 were picked up by our searches, giving a total of 567 studies from 30 different journals, 
with the five most common being Animal Cognition (112 studies; 19.8\% of the sample), Behavioural Processes (52; 9.2\%), Journal of Experimental Psychology: Animal Learning and Cognition (43; 7.6\%), Journal of Comparative Psychology (39; 6.9\%) and Animal Behaviour (34; 6.0\%).

Table 1

Coded Review Output with Corresponding Definitions

\begin{tabular}{|c|c|}
\hline Output & Definition \\
\hline Species & $\begin{array}{l}\text { All bird species involved in study (common name as referred to by authors and Latin } \\
\text { name) }\end{array}$ \\
\hline Sample size & Largest available sample size (for studies with multiple experiments) \\
\hline Site & Site name, country, and type (lab, field, farm or zoo) \\
\hline Replication & $\begin{array}{l}\text { Whether the authors defined their study as a replication (yes/no; assessed with } \\
\text { keyword search within article for term 'repli*') }\end{array}$ \\
\hline Topic & $\begin{array}{l}\text { Divided into broad topic (physical cognition, social cognition, learning, memory, } \\
\text { predisposition, or other) and detailed topic (the specific topic of the paper as } \\
\text { assessed by the coder, such as 'Theory-of-Mind' or 'causal reasoning'). Note. If a } \\
\text { study was coded using more than one of our categories, the topic reported in the } \\
\text { results reflects the first one that was extracted by the coders. }\end{array}$ \\
\hline Multiple species & Yes/no; whether or not the study tests multiple bird species \\
\hline Multiple sites & $\begin{array}{l}\text { Yes/no; whether the authors describe their study as occurring at multiple sites, usually } \\
\text { by providing more than one GPS coordinate or site name }\end{array}$ \\
\hline Non-invasive & $\begin{array}{l}\text { Yes/no; whether the study involved invasive procedures such as injection, } \\
\text { implantation, etc. }\end{array}$ \\
\hline
\end{tabular}

\section{Species and Sample Sizes}

Across the 567 studies, 141 different species were tested (Figure 2). Because 62 studies (10.9\%) tested more than one species, we had information for 621 instances of bird species tested across our studies. Of these 621, Passeriformes constituted 299 (47.1\%), Columbiformes 132 (21.3\%), Psittaciformes 78 (12.6\%) and Galliformes 71 (11.4\%). Collectively, these four orders comprised 93.4\% of our data. At the family level, the most frequently observed were Columbidae (e.g., pigeons; 132, 21.2\%), Corvidae (e.g., ravens, crows; 106, 17.1\%), Paridae (e.g., great tits, Parus major, and blue tits, Cyanistes caeruleus; 72, $11.6 \%$ ) and Phasianidae (e.g., pheasants, chickens; 71, 11.4\%), which collectively comprised $61.3 \%$ of the sample. Across all studies, the median sample size per species was 14 (minimum: 1; lower quartile: 8; upper quartile: 34; maximum: 459). Of the 40 studies with sample sizes of 100 or more, 23 of these studied Phasianidae, and were either laboratory studies of domestic chicks (e.g., Versace et al. 2017) or lab/farm studies of pheasants (e.g., Langley et al., 2020), and 10 studies were field studies. Figure 3 and Figure 4 display the distribution of sample sizes by order and family from our sample (Figure 3: the four most common orders; Figure 4: all other species). 
Lambert et al. 140

\section{Figure 2}

\section{Phylogeny of Extant Bird Orders}

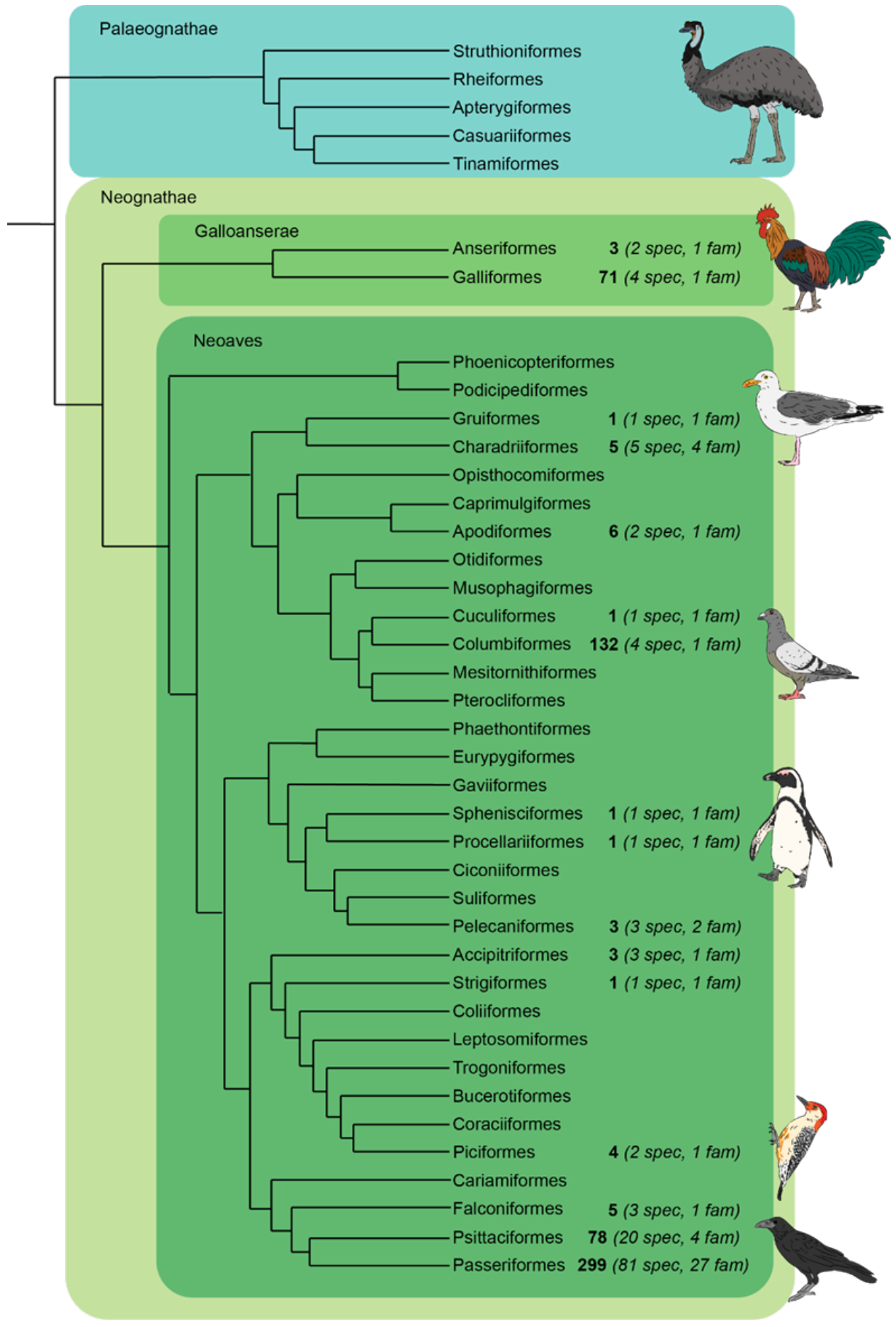

Note. Numbers in bold indicate the number of instances this order occurred in our sample; the number of species (spec) and taxonomic families (fam) are given in brackets. The phylogeny is based on Prum et al. (2015) and Kuhl et al. (2021); the branches indicate inter-order relatedness only; branch length is not representing phylogenetic distance. 


\section{Figure 3}

Violin Plots of the Sample Sizes of the Four Most Often Studied Orders in Avian Cognition from 2015-2020

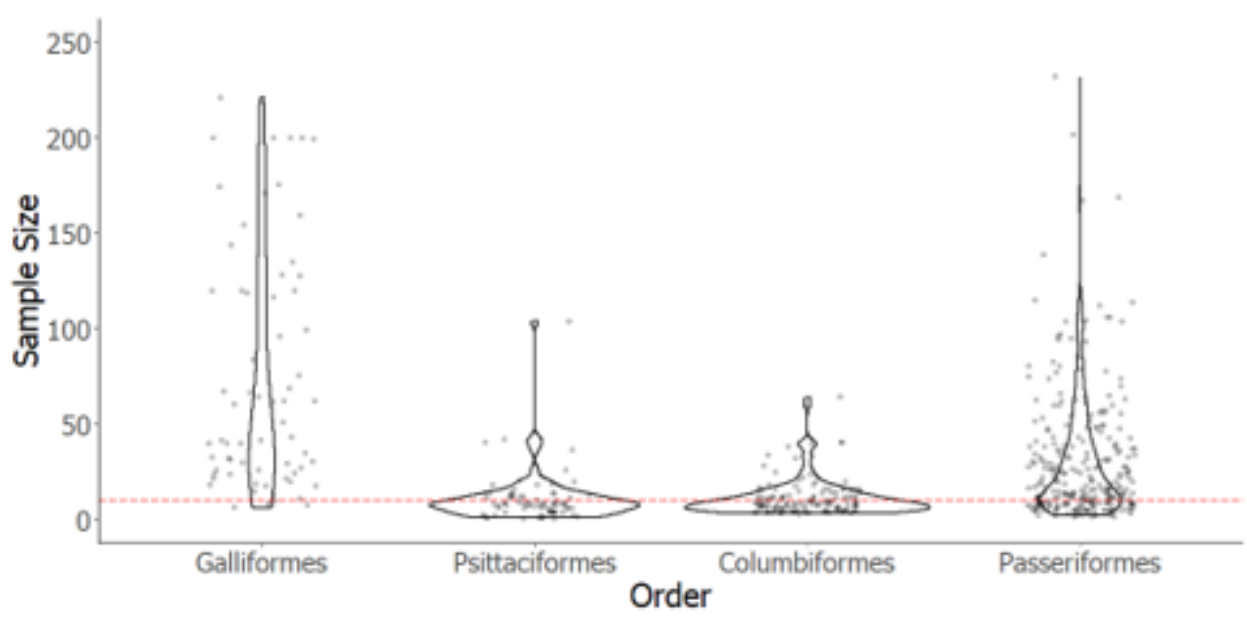

Note. The two largest studies with sample sizes of 459 (Langley et al., 2020) and 388 (Versace et al., 2017), both Galliformes (e.g., pheasants), are not displayed on the graph to improve the visibility of the smaller sample studies. Dashed line shows overall median sample size.

\section{Figure 4}

The Sample Sizes of the Less-Often Studied Orders in Avian Cognition

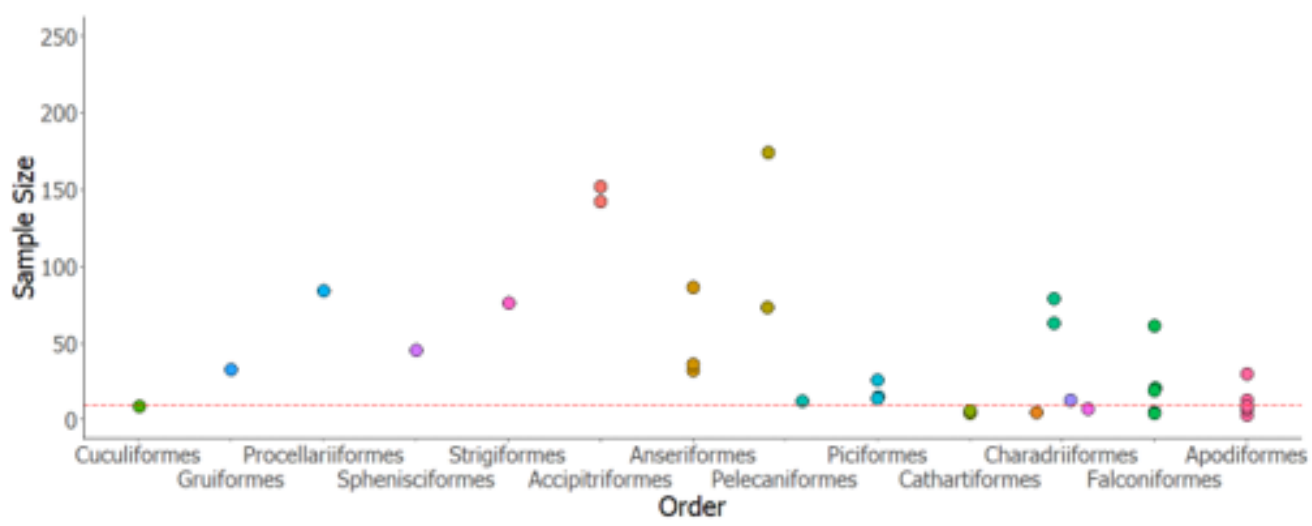

Note. Dashed line shows overall median sample size.

\section{Location and Geography}

In our sample, 54 of the $567(9.5 \%)$ studies were conducted across multiple sites. In terms of the type of site, $423(74.6 \%)$ were conducted in laboratories, $99(17.4 \%)$ at field sites, 22 in zoos (3.9\%), 17 on farms $(3.0 \%)$ and $6(1.1 \%)$ did not report their sites or were conducted at a mixture of sites (e.g., in the lab and the field). These studies were conducted across 34 different countries, 3 territories/islands (Canary Islands, French Polynesia and New Caledonia), and Antarctica. The four most common countries were: USA $(143 ; 25.2 \%)$, UK $(71 ; 12.5 \%)$, Canada $(51 ; 9.0 \%)$ and Austria $(41 ; 7.2 \%)$. Figure 5 displays the distribution of studies across the globe. 


\section{Figure 5}

The Distribution of Avian Cognition Studies from 2015-2020 Across the Globe

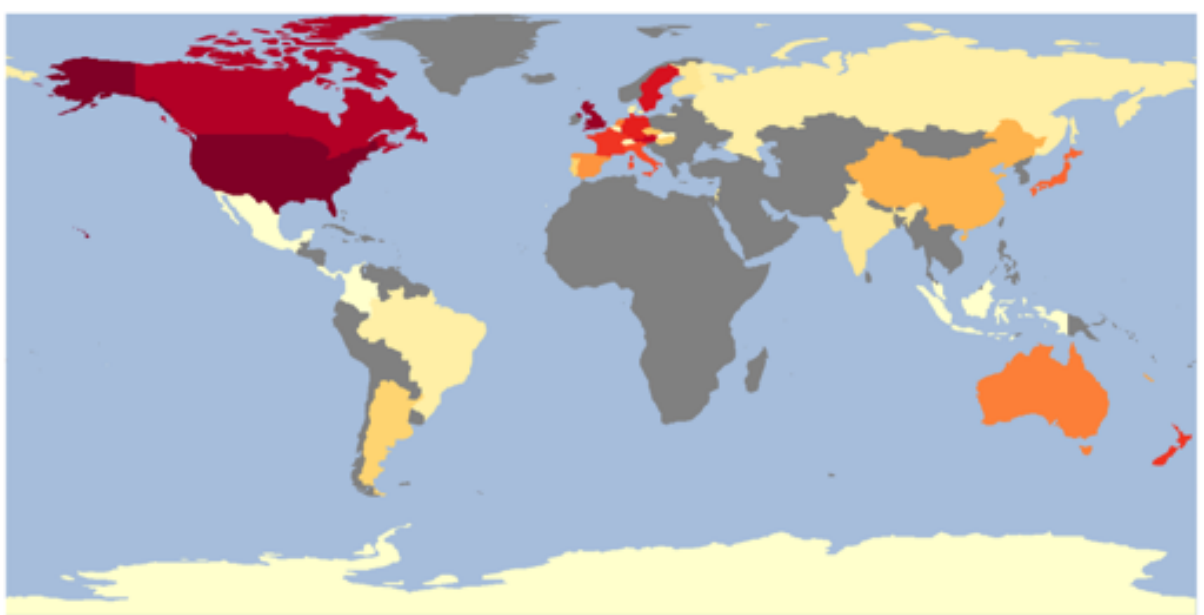

No. of studies

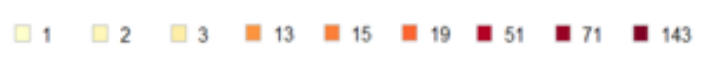

\section{Topics and Methods}

Table 2 displays the topics studied in avian cognition research between 2015 and 2020. These topics were roughly evenly distributed between journals, other than learning studies, which were overrepresented in Behavioural Processes (26 of 52 articles; 50\%) and The Journal of Experimental Psychology: Animal Learning and Cognition (22 of 43 articles; 51.1\%). Figure 6 displays the topics studied for the four most common Orders. Of the 567 studies, 42 (7.4\%) used invasive procedures, and 41 (7.2\%) contained at least one self-defined replication study or reported using the same protocol as a previous study.

\section{Figure 6}

The Distribution of Avian Cognition Topics Studied Across Columbiformes (e.g., Pigeons), Galliformes (e.g., Chickens), Passeriformes (e.g., Ravens) and Psittaciformes (e.g., Parrots)

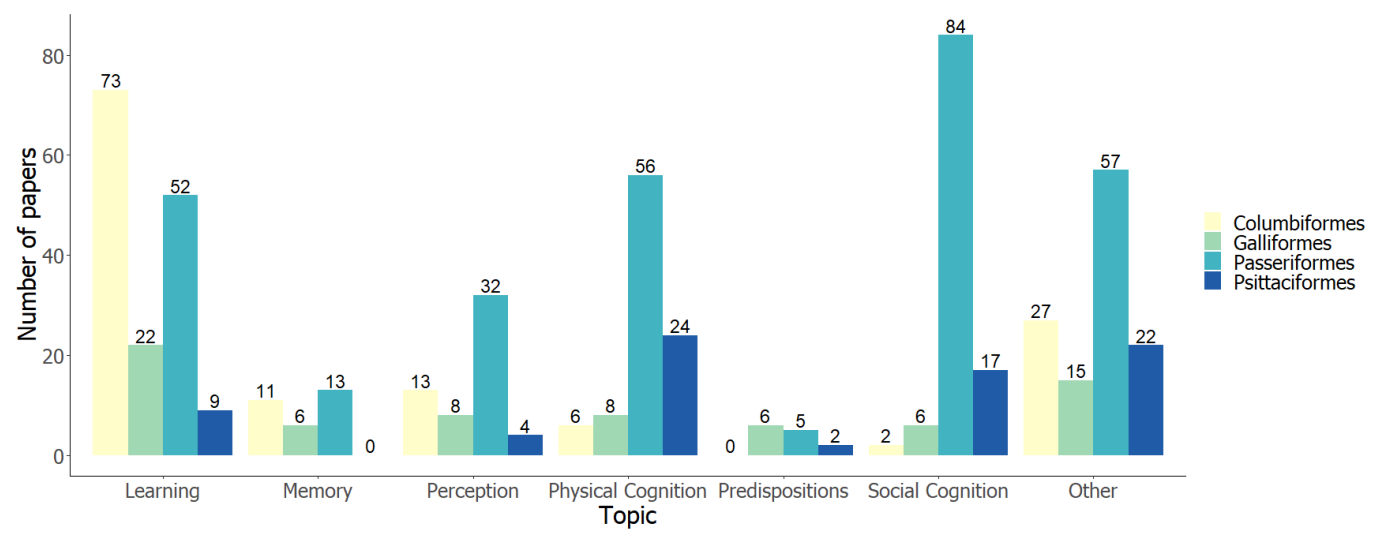


Table 2

Number of Studies Characterized Within Broad Research Topics

\begin{tabular}{|c|c|c|}
\hline Broad Topic & $\begin{array}{l}\text { Number of studies per broad } \\
\text { topic }\end{array}$ & $\begin{array}{l}\text { Examples of sub-topics included within each broad } \\
\text { topic term }\end{array}$ \\
\hline Learning & 162 & $\begin{array}{l}\text { Reversal learning, spatial learning, vocal learning, go- } \\
\text { no-go, matching-to-sample }\end{array}$ \\
\hline Memory & 34 & $\begin{array}{l}\text { Spatial memory, mental time travel, long-term } \\
\text { retention, episodic memory }\end{array}$ \\
\hline Social Cognition & 107 & $\begin{array}{l}\text { Communication, social learning, social information } \\
\text { use, inequity aversion, cooperation, theory-of-mind }\end{array}$ \\
\hline Physical Cognition & 88 & $\begin{array}{l}\text { Tool-use, string-pulling, problem-solving with } \\
\text { physical task }\end{array}$ \\
\hline Perception & 57 & Visual discrimination, acoustic discrimination \\
\hline Predispositions & 16 & $\begin{array}{l}\text { Neophobia, boldness, exploration, persistence, } \\
\text { personality }\end{array}$ \\
\hline Other & 118 & $\begin{array}{l}\text { Self-control, inhibition, meta-cognition, decision- } \\
\text { making, future planning }\end{array}$ \\
\hline
\end{tabular}

\section{Comparison to Primates}

We selected a similar review method as a recent primate review (ManyPrimates, Altschul, Beran, Bohn, Caspar, et al., 2019) in order to be able to compare findings. We found that, similarly with the primate review results, only a small proportion of bird species available $(1.41 \%)$ were represented in bird studies from 2015-2020, across the 30 journals included in our review. These species were typically from 4 main orders, with relatively small sample sizes, represented by a small number of sites (Table 3 ).

Table 3

Avian Review Results Compared with Those of a Similar Primate Review (ManyPrimates, Altschul, Beran, Bohn, Caspar, et al., 2019)

\begin{tabular}{|c|c|c|}
\hline Measure & Primates & Birds \\
\hline Number of species represented & 68 (of $>500$ species available) & 141 (of $10,000+$ species available) \\
\hline Most represented families & $\begin{array}{l}\text { Great apes }(\text { Hominidae })=38 \% \text { studies; } \\
\text { Old-World monkeys }(\text { Cercopithecidae })= \\
40 \% \text { of studies }\end{array}$ & $\begin{array}{l}\text { Columbidae (e.g., pigeons) }=21.2 \% \text { studies; } \\
\text { Corvidae }(\text { e.g., crows })=17.1 \% \text {; Phasianidae } \\
\text { (e.g., pheasants) }=11.4 \% \text {; Paridae (e.g., tits) }= \\
11.6 \% \text {. Total }=61.3 \% \text { of the sample }\end{array}$ \\
\hline Sample size range & $1-481$ & $1-459$ \\
\hline Median sample size & 7 & 14 \\
\hline $\begin{array}{l}\% \text { species with median sample } \\
\text { size under } 10 / 20\end{array}$ & $66 \%<10$ subjects & $\begin{array}{l}33.7 \% \text { of samples }<10 \text { subjects; } \\
60.4 \% \text { of samples }<20 \text { subjects }\end{array}$ \\
\hline More than 1 species per study & $19 \%$ & $10.9 \%$ \\
\hline
\end{tabular}




\section{ManyBirds Project}

\section{Outline of Project Plans}

With the ManyBirds project, our initial plan is to establish: 1. project infrastructure and 2. new collaborations 3. coordinate and contribute data to ManyBirds Study 1, and 4. coordinate \& contribute data for the ManyBirds Study 2. We aim to build on this article, as well as a multi-lab neophobia (response to novelty) study in 10 corvid species (crow family) with collaborators across 10 labs worldwide (Miller et al., 2021), to formalize the project and enhance recruitment of collaborators. Furthermore, the success of the related ManyBabies, ManyPrimates and ManyDogs projects indicates that there is general desire and support throughout the research community to contribute and collaborate within these types of projects. The ManyBirds project is a new and promising direction of research. We outline the initial planned project objectives:

\section{Establish Project Infrastructure}

The ManyBirds infrastructure involves setting up and/or maintaining: a) website (www.themanybirds.com), b) twitter account (@TheManyBirds) c) mailing list (join via website) d) email address (manybirdsproject1@gmail.com) e) open repository (e.g., OSF/ Zenodo) f) slack channels (join via website). For the research, we will communicate with collaborators via use of google docs (e.g., all materials including manuscripts), video chats, slack and email, and will require a) polls to vote on study focus and plans b) pre-registrations (OSF) c) code of practice and project policies including ethics, authorship and data sharing guidelines d) study protocols, including practice videos illustrating procedures, and requesting pilot videos from each facility to be checked by core team before data collection proceeds e) coding guides f) analyses plans g) manuscript writing. We will actively utilise Open Science practices, including pre-registration and/or Registered Reports, open data and code on repositories alongside relevant publications, pre-prints, as well as the use of open-access publishing to ensure wide accessibility, as transparency and pre-registration is necessary for effective collaborations (Allen \& Mehler, 2019). Aspects that we believe are novel for the ManyX projects include our aim to incorporate automated video analysis (e.g., Reber et al., 2021) to reduce the time investment of manual coding \& control for reliability, and include captive (lab, zoo, private residence) plus field studies to improve generalisability and increase within-species comparisons.

\section{Form New Collaborations}

We currently have several confirmed collaborators worldwide, including established avian research labs through a previous collaborative study (Miller et al., 2021) as well as access to various bird species for testing through our core team's other new and existing collaborations (including with UK zoos). We plan to utilize the findings of our present review to contact the researchers who have actively published on avian cognition in the past 5 years to invite for collaboration. Additionally, through this article and additional promotion of the project on social media (e.g., Twitter) and via our own networks (academic and zoos), we hope to open up the collaborations more widely. To promote inclusivity, like ManyPrimates, we plan to encourage contributions beyond data collection, to experimental design, data analysis and manuscript writing, thereby enabling researchers without direct access to birds - or even specifically expertise in bird research - to take part. This would allow for researchers or others outside the field to be involved, such as statistical/ modelling experts and theoretical scientists including philosophers, to encourage interdisciplinary approaches. We will include a 'sign up' survey, where collaborators can provide information such as sample sizes and species, to enable us to prepare a general master list. Each collaborator is required to obtain their own ethical approval prior to starting data collection and must provide evidence of this when submitting data, an approach that has been successfully implemented with ManyPrimates (ManyPrimates, Altschul, Beran, Bohn, Call, et al., 2019). Those collaborators that are not affiliated with 
an institution (for example testing in private settings) will be required to sign an approval form confirming that they adhere to a set of ethical standards established by the organizers prior to data collection.

\section{ManyBirds Study 1: Neophobia in Birds}

We are currently preparing a publication on individual repeatability and the influence of socioecological factors on neophobia in corvids, encompassing contributed data from 10 corvid labs worldwide (241 subjects, 10 species, 13 groups of birds; Miller et al., 2021). We followed a similar protocol as Greggor et al.'s (2020) 'Alalā study. We tested latency to touch familiar food in the presence and absence of a novel food or novel object, compared with a baseline (familiar food only), and run $3 \mathrm{x}$ to allow for repeatability (Greenberg \& Mettke-Hofmann, 2001). We used differences scores (control minus novel item values) to aim to standardize for unavoidable differences between labs. We found individual repeatability and significant effects of several socio-ecological variables, including use of urban habitats, on neophobia (Miller et al., 2021).

We are in the process of expanding on this pilot work to form our first ManyBirds study by opening up new collaborations with bird species outside the corvid family, in order to test neophobia in birds with a focus on a) species differences, b) influence of socio-ecological factors, and c) individual temporal and contextual consistency. This work involves modifying the corvid protocol to be suitable for testing other bird species (e.g., in social settings or at non-academic sites), and introducing the use of automatic video analysis software (Reber et al., 2021). Additionally, to the existing corvid data set, Mettke-Hofmann et al. (2002) tested object neophobia in 61 parrot species with comparable methods. Therefore, through new and existing collaborations we have suitable data sets available for at least 10 corvid and 61 parrot species, with a number of new data collection and collaborations confirmed. By including a wider selection of avian species, we can also incorporate phylogenetic approaches. These neophobia tests are particularly ideal for a first study due to being low-time and minimal labor requirement ( 3 conditions, 3 test 'rounds', 1 trial per condition per round per day over 3 days, repeated every 2 weeks $=9$ test days over $\sim 6-8$ weeks). There is also the option to only collect 1 test round if the opportunity to collect more is not available (similar to Mettke-Hofmann et al, 2002).

\section{ManyBirds Study 2: Topic TBC}

Following on from Study 1, we will initiate a second study within the project scope, where we adopt a consensus-based approach to selecting the research topic and experimental paradigm for each subsequent study to be voted on by the collaborative team. This will involve a list of potential suitable topics and paradigms being presented by the core team, such as self-control, short-term memory or innovation (problem-solving), with collaborators invited to vote on their preference. For example, ManyPrimates focussed first on short-term memory (ManyPrimates, Altschul, Beran, Bohn, Call, et al., 2019), then will test delay of gratification and inference by exclusion (https://manyprimates.github.io). We will select a design and appropriate research question that does not require individual separation for testing, so as to open testing up for socially housed and naïve-to-testing individuals/ species (e.g., zoos, private residences). As with Study 1, the protocols will be kept simple with low-time investment to enable crosssite standardisation, will account for species size differences, and measure discrete (e.g., correct/ incorrect) and continuous (e.g., latency to action) outcome variables.

\section{Current Stage of the ManyBirds Project}

We began setting up the project in February 2021, with the idea leading on from the neophobia in corvids study (conceived in April 2018) as a means of bringing together many corvid researchers worldwide for a collaborative study (Miller et al., 2021). Since February 2021, we have had regular ManyBirds meetings - with recorded meeting minutes and action points to enable transparency and document progress - communicated with some of the ManyPrimates core team, increased our own core team, set up the first 
study 1 team, created a dedicated email address and website, designed a logo and regularly communicate via Slack channels. In the first stage of the project, we primarily focused on writing this article, planning the project infrastructure, forming new collaborations, and initiating our first ManyBirds study (see website for more details).

\section{Core Leadership Team}

Our current core team are several early career researchers with expertise in avian cognition/ behavior, including corvids, parrots, ratites and other bird species, as well as experience in cognition/ behavioral research in humans, non-human primates, other mammals and reptiles (e.g., Farrar et al., 2020; Garcia-Pelegrin et al., 2020, 2021; Lambert et al., 2015; Lambert \& Osvath, 2018; Miller et al., 2016, 2019; Reber et al., 2013, 2021). There are also opportunities for others to join the core leadership team and/or study organising teams - as well as general collaborators - as the project develops. Contribution to the project (team or general collaborator) provides an excellent opportunity for upcoming researchers to join an international network of collaborators and establish themselves independently. This is particularly true as the project premise does not require direct access to birds and can be contributed towards from any institution. At present, we all have access to birds for data collection through existing collaborations (including in UK zoos) and contribute to the project alongside our regular positions.

\section{Limitations}

The primary limitations of the ManyBirds project are also present for most comparative studies in fact a benefit of these projects is that these limitations gain visibility. These limitations include unavoidable differences between subjects with regard to: testing sites, experimenters, conditions (e.g., testing area size), subject histories (e.g., rearing, prior research experience, training), sample sizes and individual versus social testing. To address this limitation, we will aim to test within-species to compare behavior between sites of the same species where available. Another potential limitation is that we will compare species with very different physical (e.g., body size) and cognitive capabilities, including motivation, attention and motor abilities. These issues can be addressed with careful study design, such as modifying size of novel stimuli according to each species' size, and using dependent variables such as choice (e.g., correct/incorrect) or response latency, which lend themselves to a wide range of cognitive tasks as well as well as cross-species (and cross-taxa) comparisons. In addition, testing at the same time of day with the first/ main 'meal' of the day in Study 1, can ensure (as far as possible) that subjects are equally hungry and motivated. Furthermore, with Study 2, and future subsequent studies, we will ensure ample opportunities for habituation and pre-training (if required) are included in protocols, which is particularly important for naïve, previously un-tested species/ individuals.

Through collecting data across various different sites, including labs, zoos, farms, private residences and in the field, we can compare behavior between different groups of the same species and directly test for the effect of aspects like prior history. This approach is difficult to achieve without such large-scale comparisons. Regarding likelihood of having different experimenters at each site, we will ask that collaborators submit pilot videos for checking by the core team before confirmation to proceed in data collection, to ensure that protocols are administered in as comparable a manner as possible.

Another issue with large-scale collaborative projects, especially in relatively small fields like avian cognition, is that the possibility of independent criticism from experts decreases with the size of the collaboration. If a large number of laboratories and individuals take part in the collaboration, the number of willing external critics will likely decrease. Further along these lines, one study in biomedical research reported that claims from collaborations with many authors tended to be less replicable than comparable claims from research themes with many smaller independent groups (Danchev et al., 2019). In ManyBirds, we recognize these potential problems, and to counter them will embrace a variety of transparent, and potentially-bias reducing, methods (Bishop, 2020; Nosek et al., 2018). These include pre-registration, 
registered reports and open data and code, as well as a focus on effective communication of the uncertainty in our results.

Furthermore, we advocate for a variety of approaches to avian cognition and behavior, recognizing the benefits as well as potential limitations of both multi-lab collaborative and independent lab approaches. These include the complimentary use of research designs requiring minimal time and labor investment for ManyX projects to enable testing across a wide variety of species and individuals, compared with the essential, in-depth and often lengthy (in time or number of trials/experiments) designs contributed to the field by independent labs. A final limitation is that the project requires fairly significant investment in terms of time and effort, particularly from the core team, in organizing and establishing particularly while in the early stages. The time from study conception to publication is likely to be lengthy (considerably more so than a single-species study would be), given the time required to coordinate potentially large teams of researchers in study design, data collection, coding, analysis and manuscript writing. Where possible, we may utilise Registered Reports in order to ensure methods and data analysis plans are outlined and confirmed early on (prior to data collection) for added clarity to all involved and to smooth the process of writing the final manuscript. While the scale of ManyX projects does not offer traditional incentives to all participants (e.g., first/last authorship), it does offer benefits in terms of networking, training, and inclusivity for researchers from all experience levels and backgrounds (Byers-Heinlein et al., 2020). The high participation in our initial corvid neophobia project, coupled with the success of ManyBabies and ManyPrimates, shows an encouraging level of support for such collaborative, open-science endeavors.

\section{Expected Project Outcomes and Future Directions}

ManyX projects have proven to be a valuable tool for large-scale comparisons, but require significant management, particularly at the beginning. We are working to take the ManyBirds project from a strong idea to an established infrastructure for fully collaborative and open avian cognition/behavior research and completion of the first studies. These outcomes would place our team and the project in an excellent position to attract future funding to support subsequent studies, through demonstrated publications and collaborations. We will actively encourage collaborators to engage in science dissemination via conferences and meeting presentations, social media and publication media output. We hope to be able to arrange a workshop for collaborators in future, if funding can be secured.

The project has potential for far-reaching consequences with regard to advancing the field of comparative cognition and animal behavior, by both promoting transparency and reliability, as well as providing the data necessary to understand the evidential value of previously published single-site studies - which currently dominate the avian cognition literature (Farrar et al., 2020). It will allow for a wider focus on research questions encompassing the evolution of avian cognition and behavior, such as testing the drivers of cognition in relation to socio-ecological factors, like diet, sociality and habitat use, as well as comparative, phylogenetic, developmental and longitudinal approaches. We also hope to encourage others to establish similar projects in other taxa groups, like reptiles, by outlining the process of establishing this project, and promote collaborations between ManyX projects to enable the investigation of the evolution of cognition more generally, i.e., across birds, mammals, as well as potentially in humans.

Furthermore, there are recent calls for integrating cognition in applied animal conservation and welfare (Greggor et al., 2014). Our project facilitates collaborations with avian facilities holding hugely under-/not represented species, often in small numbers - zoos in particular are a key under-utilized resource as highlighted in our present review. ManyBirds, by nature, encourages contributions regardless of individual facility samples, as these can be increased by combining data across facilities. In zoos, species are often endangered and have active conservation efforts, therefore are ideal candidates for gathering cognitive data for application to conservation actions (Greggor et al., 2014). Similarly, welfare can be improved by providing published cognitive data, such as in farm animals like chickens (Marino, 2017). Finally, voluntary participation in cognitive experiments can be enriching and mentally stimulating for captive animals (Clark, 2017; Hopper, 2017). 


\section{Conclusion}

The formation of large collaborative projects, such as ManyBabies, ManyPrimates, and ManyDogs, indicates a shared desire from the scientific community to collaborate towards a common goal of inquiry. As outlined here, birds occupy a diverse range of ecological, geographical, and social niches. As such, the investigation of avian cognition at a comparative level provides insight into the diverse evolutionary pressures that might have selected for different behavioral and cognitive adaptations. Moreover, the possibility of comparison of a wider range of distinct avian species might elucidate on the proposed theorems for convergent evolution of intelligence amongst different taxa. However, to do so, larger sample sizes and a wider coverage of the different species within the taxa are necessary. Our review of the current state of the field revealed that while 141 species of birds were represented, the median sample size was only 14 subjects. Moreover, comparisons between different bird species were rare, with only $10.9 \%$ of the studies directly comparing more than one species using the same methodology.

The ManyBirds project outlined here provides an optimal infrastructure for collaborative testing and theorization of avian cognition and behavior by encouraging both input from established labs and field researchers, while also providing zoos, farms and bird holders in private collections (including private homes), the opportunity to collaborate in such endeavor. The implementation of this collaborative infrastructure will aid the reliability of the data collected, by offering larger sample sizes, a diverse array of avian species from which to obtain data, and by stipulating and systematizing the methodology used to obtain it. Ultimately, the creation of a ManyBirds infrastructure will provide unparalleled insight into the evolution of avian cognition by nurturing collaboration, replicability, and data openness. This project will aid the avian cognition and behavior field by facilitating the means to acquire larger comparative datasets from which to extrapolate wider scientific inferences.

Data Availability Statement: Data and coding script are available at: osf.io/g87pz

Author Contributions: Conceptualisation, R. M. and M. L. L.; Methodology, all authors; formal analysis, B. F.; Investigation, all authors; data curation, all authors; writing (original draft and editing), all authors; visualisation, B. F. and S. R.; project management and administration, R. M. All authors have read and agreed to the published version of the manuscript.

Funding: R.M. was supported by the Career Support Fund from University of Cambridge. M. L. L. was supported by a Lise Meitner Grant from the Austrian Science Fund (FWF, grant: M-2563). S.A.R. was supported by LMK Foundation and the HT faculty, Lund University.

Conflicts of Interest: The authors declare no conflict of interest. The funder had no role in the design of the study; in the collection, analyses, or interpretation of the data in the writing of the manuscript, or in the decision to publish the results.

Ethics: This review required no animal testing so ethical approval was not required.

\section{Acknowledgements}

The authors are grateful to Michael Beran, Manuel Bohn and an anonymous reviewer for their helpful comments on this manuscript.

\section{References}

Allen, C., \& Mehler, D. M. A. (2019). Open science challenges, benefits and tips in early career and beyond. PLoS Biology, 17(5), e3000246. 
Barth, J., Reaux, J. E., \& Povinelli, D. J. (2005). Chimpanzees' (Pan troglodytes) use of gaze cues in object-choice tasks: Different methods yield different results. Animal Cognition, 8(2), 84-92.

Beach, F. A. (1950). The Snark was a Boojum. American Psychologist, 5(4), 115-124.

Beran, M. (2018). Replication and pre-registration in comparative psychology. International Journal of Comparative Psychology, 2018, 31.

Bishop, D. (2019). Rein in the four horsemen of irreproducibility. Nature, 568(7753), 435-436.

Bishop D. V. (2020). The psychology of experimental psychologists: Overcoming cognitive constraints to improve research: The 47th Sir Frederic Bartlett Lecture. Quarterly Journal of Experimental Psychology, 73(1), 119.

Brecht, K. F., Legg, E. W., Nawroth, C., Fraser, H., \& Ostojić, L. (2021). The status and value of replications in animal behavior science. Animal Behavior and Cognition, 8(2), 97-106.

Briscoe, S. D., Albertin, C. B., Rowell, J. J., \& Ragsdale, C. W. (2018). Neocortical association cell types in the forebrain of birds and alligators. Current Biology, 28(5), 686-696.e6.

Brodmann, K. (1909). Vergleichende Lokalisationslehre der Grosshirnrinde in ihren Prinzipien dargestellt auf Grund des Zellenbaues. Barth.

Byers-Heinlein, K., Bergmann, C., Davies, C., Frank, M. C., Hamlin, J. K., Kline, M., Kominsky, J. F., Kosie, J. E., Lew-Williams, C., Liu, L., Mastroberardino, M., Singh, L., Waddell, C. P. G., Zettersten, M., \& Soderstrom, M. (2020). Building a collaborative psychological science: Lessons learned from ManyBabies 1. Canadian Psychology/Psychologie Canadienne, 61(4), 349-363.

Chittka, L., Rossiter, S. J., Skorupski, P., \& Fernando, C. (2012). What is comparable in comparative cognition? Philosophical Transactions of the Royal Society B: Biological Sciences, 367(1603), 2677-2685.

Clark, F. E. (2017). Cognitive enrichment and welfare: Current approaches and future directions. Animal Behavior and Cognition, 4(1), 52-71.

Danchev, V., Rzhetsky, A., \& Evans, J. A. (2019). Meta-research: Centralized scientific communities are less likely to generate replicable results. Elife, 8, e43094.

Diamond, J., \& Bond, A. B. (2003). A comparative analysis of social play in birds. Behaviour, 140(8), 1091-1115.

Diekamp, B., Gagliardo, A., \& Güntürkün, O. (2002). Nonspatial and subdivision-specific working memory deficits after selective lesions of the avian prefrontal cortex. Journal of Neuroscience, 22(21), 9573-9580.

Donahue, C. J., Glasser, M. F., Preuss, T. M., Rilling, J. K., \& Van Essen, D. C. (2018). Quantitative assessment of prefrontal cortex in humans relative to nonhuman primates. Proceedings of the National Academy of Sciences, 115(22), E5183-E5192.

Dos Reis, M., Thawornwattana, Y., Angelis, K., Telford, M. J., Donoghue, P. C. J., \& Yang, Z. (2015). Uncertainty in the timing of origin of animals and the limits of precision in molecular timescales. Current Biology, 25(22), 2939-2950.

Durstewitz, D., Kröner, S., Hemmings Jr, H. C., \& Güntürkün, O. (1998). The dopaminergic innervation of the pigeon telencephalon: Distribution of DARPP-32 and co-occurrence with glutamate decarboxylase and tyrosine hydroxylase. Neuroscience, 83(3), 763-779.

Emery, N. J., \& Clayton, N. S. (2004). The mentality of crows: Convergent evolution of intelligence in corvids and apes. Science, 306(5703), 1903-1907.

Farrar, B. G., Boeckle, M., \& Clayton, N. S. (2020). Replications in comparative cognition: What should we expect and how can we improve? Animal Behavior and Cognition, 7(1), 1-22.

Farrar, B. G., Voudouris, K., \& Clayton, N. S. (2021). Replications, comparisons, sampling and the problem of representativeness in animal cognition research. Animal Behavior and Cognition, 8(2), 273-295.

Field, D. J., Bercovici, A., Berv, J. S., Dunn, R., Fastovsky, D. E., Lyson, T. R., Vajda, V., \& Gauthier, J. A. (2018). Early evolution of modern birds structured by global forest collapse at the end-Cretaceous mass extinction. Current Biology, 28(11), 1825-1831.

Freckleton, R. P., Harvey, P. H., \& Pagel, M. (2002). Phylogenetic analysis and comparative data: A test and review of evidence. The American Naturalist, 160, 712-726.

Garcia-Pelegrin, E., Schnell, A. K., Wilkins, C., \& Clayton, N. S. (2020). An unexpected audience. Science, 369(6510), 1424-1426.

Garcia-Pelegrin, E., Schnell, A. K., Wilkins, C., \& Clayton, N. S. (2021). Exploring the perceptual inabilities of Eurasian jays (Garrulus glandarius) using magic effects. Proceedings of the National Academy of Sciences, $118(24)$, e2026106118.

Gelman, A., \& Carlin, J. (2014). Beyond power calculations: Assessing type S (sign) and type M (magnitude) errors. Perspectives on Psychological Science, 9(6), 641-651.

Gill, F., Donsker, D., \& Rasmussen, P. (2021). IOC world bird list (v11. 1). doi:10.14344/IOC.ML.11.1. 
Greenberg, R., \& Mettke-Hofmann, C. (2001). Ecological aspects of neophobia and neophilia in birds. Current Ornithology, 16, 119-178.

Greggor, A. L., Clayton, N. S., Phalan, B., \& Thornton, A. (2014). Comparative cognition for conservationists. Trends in Ecology \& Evolution, 29(9), 489-495.

Greggor, A. L., Masuda, B., Flanagan, A. M., \& Swaisgood, R. R. (2020). Age-related patterns of neophobia in an endangered island crow: Implications for conservation and natural history. Animal Behaviour, 160, 61-68.

Güntürkün, O. (1997). Cognitive impairments after lesions of the neostriatum caudolaterale and its thalamic afferent in pigeons: Functional similarities to the mammalian prefrontal system? Journal Fur Hirnforschung, 38(1), $133-143$.

Güntürkün, O. (2005). The avian 'prefrontal cortex' and cognition. Current Opinion in Neurobiology, 15(6), 686693.

Güntürkün, O. (2012). The convergent evolution of neural substrates for cognition. Psychological Research, 76(2), 212-219.

Güntürkün, O., \& Bugnyar, T. (2016). Cognition without cortex. Trends in Cognitive Sciences, 20(4), 291-303.

Herculano-Houzel, S. (2017). Numbers of neurons as biological correlates of cognitive capability. Current Opinion in Behavioral Sciences, 16, 1-7.

Hodos, W., \& Campbell, C. B. G. (1969). Scala naturae: Why there is no theory in comparative psychology. Psychological Review, 76(4), 337-350.

Hopper, L. M. (2017). Cognitive research in zoos. Current Opinion in Behavioral Sciences, 16, 100-110.

Jacobs, I., Kabadayi, C., \& Osvath, M. (2019). The development of sensorimotor cognition in common ravens (Corvus corax) and its comparative evolution. Animal Behavior and Cognition, 6, 194-212.

Jarvis, E. D., Güntürkün, O., Bruce, L., Csillag, A., Karten, H., Kuenzel, W., Medina, L., Paxinos, G., Perkel, D. J., \& Shimizu, T. (2005). Avian brains and a new understanding of vertebrate brain evolution. Nature Reviews Neuroscience, 6(2), 151-159.

Kabadayi, C., Taylor, L. A., von Bayern, A. M. P., \& Osvath, M. (2016). Ravens, New Caledonian crows and jackdaws parallel great apes in motor self-regulation despite smaller brains. Royal Society Open Science, 3(4), 160104.

Klein, R. A., Ratliff, K. A., Vianello, M., Adams Jr, R. B., Bahník, Š., Bernstein, M. J., Bocian, K., Brandt, M. J., Brooks, B., \& Brumbaugh, C. C. (2014). Investigating variation in replicability. Social Psychology, 45, 142152.

Klein, R. A., Vianello, M., Hasselman, F., Adams, B. G., Adams Jr, R. B., Alper, S., Aveyard, M., Axt, J. R., Babalola, M. T., \& Bahník, S. (2018). Many Labs 2: Investigating variation in replicability across samples and settings. Advances in Methods and Practices in Psychological Science, 1(4), 443-490.

Krasheninnikova, A., Chow, P. K. Y., \& von Bayern, A. M. P. (2020). Comparative cognition: Practical shortcomings and some potential ways forward. Canadian Journal of Experimental Psychology/Revue Canadienne de Psychologie Expérimentale, 74(3), 160-169.

Kuhl, H., Frankl-Vilches, C., Bakker, A., Mayr, G., Nikolaus, G., Boerno, S. T., Klages, S., Timmermann, B., \& Gahr, M. (2021). An unbiased molecular approach using 3'-UTRs resolves the avian family-level tree of life. Molecular Biology and Evolution, 38(1), 108-127.

Lambert, M. L., Jacobs, I., Osvath, M., \& von Bayern, A. M. P. (2019). Birds of a feather? Parrot and corvid cognition compared. Behaviour, 156(5-8), 505-594.

Lambert, M. L., \& Osvath, M. (2018). Comparing chimpanzees' preparatory responses to known and unknown future outcomes. Biology Letters, 14(9), 20180499.

Lambert, M. L., Seed, A. M., \& Slocombe, K. E. (2015). A novel form of spontaneous tool use displayed by several captive greater vasa parrots (Coracopsis vasa). Biology Letters, 11(12), 20150861.

Lange, F. (2019). Are difficult-to-study populations too difficult to study in a reliable way? Lessons learned from meta-analyses in clinical neuropsychology. European Psychologist, 25(1), 41-50.

Langley, E. J. G., Adams, G., Beardsworth, C. E., Dawson, D. A., Laker, P. R., van Horik, J. O., Whiteside, M. A., Wilson, A. J., \& Madden, J. R. (2020). Heritability and correlations among learning and inhibitory control traits. Behavioral Ecology, 31(3), 798-806.

Longrich, N. R., Tokaryk, T., \& Field, D. J. (2011). Mass extinction of birds at the cretaceous-paleogene (K-Pg) boundary. Proceedings of the National Academy of Sciences of the United States of America, 108(37), 1525315257.

MacLean, E. L., Hare, B., Nunn, C. L., Addessi, E., Amici, F., Anderson, R. C., Aureli, F., Baker, J. M., Bania, A. E., Barnard, A. M., Boogert, N. J., Brannon, E. M., Bray, E. E., Bray, J., Brent, L. J. N., Burkart, J. M., Call, J., Cantlon, J. F., Cheke, L. G., Clayton, N. S., Delgado, M. M., DiVincenti, L. J., Fujita, K., Hermann, E., Hiramatsu, C., Jacobs, L.F., Jordan, K. E., Laude, J. R., Leimgruber, K. L., Messer, E. J. E., Moura, A. C. 
A., Ostojić, L., Picard, A., Platt, M. L., Plotnik, J. M., Range, F., Reader, S. M., Reddy, R. B., Sandel, A. A., Santos, L. R., Schumann, K., Seed, A. M., Sewall, K. B., Shaw, R. C., Slocombe, K. E., Su, Y., Takimoto, A., Tan, J., Tao, R., van Schaik, C. P., Virányi, Z., Visalberghi, E., Wade, J. C., Watanabe, A., Widness, J., Young, J. K., Zentall, T. R., \& Zhao, Y. (2014). The evolution of self-control. Proceedings of the National Academy of Sciences of the United States of America, 111(20), E2140-E2148.

ManyPrimates, Altschul, D., Bohn, M., Canteloup, C., Ebel, S. J., Hanus, D., Hernandez-Aguilar, R., Joly, M., Keupp, S., Llorente, M., O’Madagain, C., Petkov, C. I., Proctor, D., Motes-Rodrigo, A., Sutherland, K., Szabelska, A., Taylor, D., Völter, C. J., \& Wiggenhauser, N. G. (in press). Collaboration and open science initiatives in primate research. In B. L. Schwartz \& M. J. Beran (Eds.), Primate cognitive studies. Cambridge University Press.

ManyPrimates, Altschul, D. M., Beran, M. J., Bohn, M., Call, J., DeTroy, S., Duguid, S. J., Egelkamp, C. L., Fichtel, C., Fischer, J., Flessart, M., Hanus, D., Haun, D. B. M., Haux, L. M., Hernandez-Aguilar, R., Herrmann, E., Hopper, L. M., Joly, M., Kano, F., Keupp, S., Melis, A. P., Rodrigo, A. M., Ross, S. R., Sánchez-Amaro, A., Sato, Y., Schmitt, V., Schweinfurth, M. K., Seed, A. M., Taylor, D., Völter, C. J., Warren, E., \& Watzek, J. (2019). Establishing an infrastructure for collaboration in primate cognition research. PLoS One, 14(10), e0223675.

ManyPrimates, Altschul, D. M., Beran, M. J., Bohn, M., Caspar, K. R., Fichtel, C., Försterling, M., Grebe, N. M., Hernandez-Aguilar, R. A., Kwok, S. C., Llorente, M., Motes-Rodrigo, A., Proctor, D., Sánchez-Amaro, A., Simpson, E. A., Szabelska, A., Taylor, D., van der Mescht, J., Völter, C. J., \& Watzek, J. (2019). Collaborative open science as a way to reproducibility and new insights in primate cognition research. Japanese Psychological Review, 62(103), 205-220.

Marino, L. (2017). Thinking chickens: A review of cognition, emotion, and behavior in the domestic chicken. Animal Cognition, 20(2), 127-147.

Mettke-Hofmann, C., Winkler, H., \& Leisler, B. (2002). The significance of ecological factors for exploration and neophobia in parrots. Ethology, 108(3), 249-272.

Miller, R., Boeckle, M., Jelbert, S. A., Frohnwieser, A., Wascher, C. A. F., \& Clayton, N. S. (2019). Self-control in crows, parrots and nonhuman primates. Wiley Interdisciplinary Reviews: Cognitive Science, 10(6), e1504.

Miller, R., Lambert, M. L., Frohnwieser, A., Brecht, K. F., Bugnyar, T., Crampton, I., Garcia-Pelegrin, E., Gould, K., Greggor, A. L., Izawa, E.-I., Kelly, D. M., Li, Z., Luo, Y., Luong, L. B., Massen, J. J. M., Neider, A., Reber, S. A., Schiestl, M., Seguchi, A., Sepehri, P., Stevens, J. R., Taylor, A. H., Wang, L., Wolff, L. M., Zhang, Y., \& Clayton, N. S. (2021). Socio-ecological correlates of neophobia in corvids. Current Biology, 32(1), 7485 .

Miller, R., Logan, C. J., Lister, K., \& Clayton, N. S. (2016). Eurasian jays do not copy the choices of conspecifics, but they do show evidence of stimulus enhancement. PeerJ, 4, e2746.

Nieder, A., Wagener, L., \& Rinnert, P. (2020). A neural correlate of sensory consciousness in a corvid bird. Science, $369(6511), 1626-1629$.

Nosek, B. A., Ebersole, C. R., DeHaven, A. C., \& Mellor, D. T. (2018). The preregistration revolution. Proceedings of the National Academy of Sciences, 115(11), 2600-2606.

Olkowicz, S., Kocourek, M., Lučan, R. K., Porteš, M., Fitch, W. T., Herculano-Houzel, S., \& Němec, P. (2016). Birds have primate-like numbers of neurons in the forebrain. Proceedings of the National Academy of Sciences, $113(26), 7255-7260$.

Open Science Collaboration (2015). Estimating the reproducibility of psychological science. Science, 349(6251).

Prum, R. O., Berv, J. S., Dornburg, A., Field, D. J., Townsend, J. P., Lemmon, E. M., \& Lemmon, A. R. (2015). A comprehensive phylogeny of birds (Aves) using targeted next-generation DNA sequencing. Nature, 526(7574), 569-573.

Reber, S. A., Oh, J., Janisch, J., Stevenson, C., Foggett, S., \& Wilkinson, A. (2021). Early life differences in behavioral predispositions in two Alligatoridae species. Animal Cognition, 24, 753-764.

Reber, S. A., Townsend, S. W., \& Manser, M. B. (2013). Social monitoring via close calls in meerkats. Proceedings of the Royal Society B: Biological Sciences, 280(1765), 20131013.

Schubiger, M. N. (2019). Optimising tests of primate cognition: Towards valid species comparisons. University of Zurich.

Seed, A., Emery, N., \& Clayton, N. (2009). Intelligence in corvids and apes: A case of convergent evolution? Ethology, $115(5), 401-420$.

Shettleworth, S. J. (2010). Clever animals and killjoy explanations in comparative psychology. Trends in Cognitive Sciences, 14(11), 477-481. 
Shubin, N., Tabin, C., \& Carroll, S. (2009). Deep homology and the origins of evolutionary novelty. Nature, 457(7231), 818-823.

Smith, P. L., \& Little, D. R. (2018). Small is beautiful: In defense of the small-N design. Psychonomic Bulletin \& Review, 25(6), 2083-2101.

Stacho, M., Herold, C., Rook, N., Wagner, H., Axer, M., Amunts, K., \& Güntürkün, O. (2020). A cortex-like canonical circuit in the avian forebrain. Science, $369(6511)$, eabc5534.

Stevens, J. R. (2017). Replicability and reproducibility in comparative psychology. Frontiers in Psychology, 8, 862.

Tecwyn, E. (2021). Doing Reliable Research in Comparative Psychology: Challenges and Proposals for Improvement. Journal of Comparative Psychology, 135(3), 291-301.

Thorndike, E. L. (1911). Animal intelligence, Darien, Ct. Hafner.

van Horik, J. O., Clayton, N. S., \& Emery, N. J. (2012). Convergent evolution of cognition in corvids, apes and other animals. In J. Vonk \& T. K. Shackelford (Eds), Oxford handbook of comparative evolutionary psychology (pp. 80-101). Oxford University Press.

Versace, E., Spierings, M. J., Caffini, M., Ten Cate, C., \& Vallortigara, G. (2017). Spontaneous generalization of abstract multimodal patterns in young domestic chicks. Animal Cognition, 20(3), 521-529.

Völter, C. J., Tinklenberg, B., Call, J., \& Seed, A. M. (2018). Comparative psychometrics: establishing what differs is central to understanding what evolves. Philosophical Transactions of the Royal Society B: Biological Sciences, 373(1756), 20170283.

Von Eugen, K., Tabrik, S., Güntürkün, O., \& Ströckens, F. (2020). A comparative analysis of the dopaminergic innervation of the executive caudal nidopallium in pigeon, chicken, zebra finch, and carrion crow. Journal of Comparative Neurology, 528(17), 2929-2955.

Würbel, H. (2000). Behaviour and the standardization fallacy. Nature Genetics, 26(3), 263.

Xu, X., You, H., Du, K., \& Han, F. (2011). An Archaeopteryx-like theropod from China and the origin of Avialae. Nature, 475(7357), 465-470. 